\title{
Rapid Epidemiological Assessment of Lymphatic Filariasis in Northern Taraba Focus, Nigeria
}

\author{
Elkanah Sambo Obadiah ${ }^{1}$, Elkanah Deborah Sambo ${ }^{1}$, Madara Adamu Alhaji ${ }^{2}$, \\ Akafyi Danlami Elisha ${ }^{3,}$, Kela Santaya ${ }^{4}$, Anyanwu Greg ${ }^{4}$, Samaila Adamu $^{4}$ \\ ${ }^{1}$ Department of Biological Sciences, Faculty of Natural Sciences, Taraba State University, Jalingo, Nigeria \\ ${ }^{2}$ Department of Biological Sciences, Faculty of Sciences, University of Abuja, Abuja, Nigeria \\ ${ }^{3}$ Department of Biological Sciences, Faculty of Science, Ahmadu Bello University, Zaria, Nigeria \\ ${ }^{4}$ Applied Parasitology Unit, Department of Biological Science, Faculty of Science, Abubakar Tafawa Balewa University, Bauchi, Nigeria
}

\section{Email address:}

elkana03@yahoo.com (E. S. Obadiah), debbyelkanah@gmail.com (E. D. Sambo), alhajimadara@yahoo.com (M. A. Alhaji), dakafyippp@gmail.com (A. D. Elisha),prof.santayakela@gmail.com (K. Santaya),greg.anyanwu@yahoo.com (A. Greg), adamusamaila13@yahoo.com (S. Adamu)

${ }^{*}$ Corresponding author

\section{To cite this article:}

Elkanah Sambo Obadiah, Elkanah Deborah Sambo, Madara Adamu Alhaji, Akafyi Danlami Elisha, Kela Santaya, Anyanwu Greg, Samaila Adamu. Rapid Epidemiological Assessment of Lymphatic Filariasis in Northern Taraba Focus, Nigeria. International Journal of Infectious Diseases and Therapy. Vol. 3, No. 1, 2018, pp. 6-12. doi: 10.11648/j.ijidt.20180301.12

Received: September 12, 2017; Accepted: September 30, 2017; Published: January 15, 2018

\begin{abstract}
This study was undertaken to determine the prevalence of Lymphatic Filariasis in eleven (11) foci communities of northern Taraba state. Blood samples were collected by finger prick method to determine the presence of filarial antigen in serum using immunochromatographic card test. Questionnaires and physical examinations were used to assess clinical manifestations associated with the infection. The result showed that 101/336 (30.02\%) were positive for W. bancrofti circulating filarial antigen. The circulating filarial antigen prevalence among the eleven communities differ significantly $(\mathrm{p}<$ $0.05)$. There was no significant difference between antigenaemia positive males $(32.0 \%)$ and female $(27.7 \%)\left(\chi^{2}=0.491 \mathrm{df} 1\right.$, $\mathrm{P}>0.05)$. However, the antigenaemia prevalence among the age groups differs, with ages 51-60 years having the highest prevalence among male and ages 41-50 years among female respectively $\left(\chi^{2}=11.424\right.$, df $\left.6, P<0.05\right)$. Chronic clinical manifestation observed include Hydrocoel (17.12\%) and lymphoedema of limbs (20.08\%). Female had significant proportion of those with lymphoedema (14.8\%). The findings showed a high prevalence of the infection which is far above the World Health Organisation threshold level of $\geq 1 \%$ prevalence as well as significant prevalence of clinical manifestations. Therefore integrated intervention programme is required in the study area.
\end{abstract}

Keywords: Epidemiology, Assessment, Lymphatic Filariasis, Immunochromatographic Card, Diagnosis, Clinical Manifestations, Prevalence

\section{Introduction}

Lymphatic filariasis (LF) is a neglected tropical disease caused by the following parasitic nematodes, $W$. bancrofti, Brugia malayi and B. timori. These parasites are transmitted by many species of mosquitoes in four genera, Anopheles spp, Culex spp, Aedes spp and Mansoni spp [1].

Recent Global Burden of Disease (GBD) showed an estimated LF prevalence rate of $2.78 \%$ [2]. It is estimated that there are about 1.2 billion people who are at risk of the disease in the 83 countries in which LF is endemic $(20 \%$ of the world population); and over 128 million people are infected [3]

About 76 million people in the world are estimated to be suffering from the hidden disease or subclinical renal, respiratory, lymphatic and genital complications associated with LF [4]. Of the 128 million people infected globally by LF, $91 \%$ of them are due to $W$. bancrofti while $B$. malayi and B. timori account for the other $9 \%$ burden [5].

A recent estimation of the impact of MDA during the past 
13 years suggests $>96.71$ million cases were prevented or cured, yet as many as 36 million cases of hydrocele and lymphoedema remain. Of the total population requiring preventative chemotherapy, $57 \%$ live in the South-East Asia Region (9 countries) and 37\% live in the African Region (35 countries) [6].

In Africa, 35 countries are endemic, and Nigeria is believed to bear the highest burden of LF, with an estimated 80 to 120 million people at risk [7] [2]. In endemic communities, LF is most prevalent in the rural and slum areas, predominantly affecting the poorest of the poor [8] [9].

However, recent work by [10] showed that 66 of the 72 countries are currently endemic and for a further 17 countries where LF is no longer endemic. The study highlighted a restricted and highly heterogeneous distribution in subSaharan Africa, with transmission more widespread in West Africa compared to east, central and southern Africa.

The clinical manifestations of lymphatic filariasis range from periodic reoccurring attacks of localized inflammation, tenderness and pain, often accompanied by fever, nausea and vomiting known as acute adenolymphagitis (ADL) to chronic symptoms including lymphoedema, elephantiasis and chyluria [11]. The visible manifestations of the disease are severe and disfiguring. Lymphoedema and elephantiasis of the limbs and or genitalia, hydrocoel and scrotal pathology in men, recurrent infections associated with damaged lymphatics, chyluria or abnormalities of the renal functions occur in an estimated 44 million people [12]. The socioeconomic and psychological burden of the disease are enormous and included direct cost of treatment, losses resulting from incapacitation and loss of labour [13].

Reduced productivity experienced by LF patients results in hundreds of millions of dollars in economic losses each year. Recognizing the economic impact, disability and social stigma caused by LF and the availability of strategies to prevent infections and manage morbidity, WHO Member States committed to the global elimination of the disease as a public health problem [14]

Unprecedented and unplanned urbanization, overcrowding and deteriorating sanitary conditions in both urban and rural areas is believed to be exacerbating the transmission of this mosquito borne disease in Nigeria. [15]. More epidemiological and socio-economic information is needed on the disease distribution and intensity in endemic areas in Nigeria.

In view of the current elimination program which assumes no differences within the parasite population in West Africa, further studies are required in order to formulate appropriate strategies should there be genetic variability in W. bancrofti that may affect the success of MDA programs [16].

This study was therefore designed to determine the status of the infection in eleven communities of Northern Taraba focus despite the on-going preventive chemotherapy, called Mass Drug Administration (MDA), and provide epidemiological data where there are reported cases of clinical manifestation and active transmission of the infection in the study area.

\section{Materials and Methods}

The state lies approximately between Latitude $6^{\circ} 25^{\prime}$ and $9^{\circ} 30^{\prime} \mathrm{N}$ and Longitude $9^{\circ} 30^{\prime}$ and $11^{\circ} 45^{\prime} \mathrm{E}$. It is bordered on the West by Nassarawa and Plateau state, South East by Bauchi and Gombe States, North East by Adamawa State and South west by Benue state. Taraba state is boarded to the East by the Federal Republic of Cameroon which is an international boundary. The state has a land area of about 60 , 291 sq.km with a total population of 2, 300,736 persons based on the 2006 National Census Figures [17]. About 43, $453 \mathrm{~km}^{2}$ of Taraba state is plain land, while $12,929 \mathrm{~km}^{2}$ is highland. The remaining $3,909 \mathrm{~km}^{2}$ is wetland. Great majority of the people in the state are living in rural settlement consisting of hamlets and villages, the majority of the inhabitants live in rural agricultural areas with farming as the major occupation. The L. G. A has numerous streams transverse villages/communities and draining into the major river Benue. Communities rely mainly on the streams and river for water supply. Domestic water is usually stored in and around homes in drums, clay pots and all sorts of metal and plastic containers which provide permanent breeding sites for mosquitoes and ecological associates.

\subsection{Ethical Clearance and Permission}

The study receive ethical clearance certificate from an institutional health research committee and ethical approval of Taraba state Ministry of Health. Also additional permission were sought and obtained from Local Government chairmen, Primary Health Care (PHC) department, Districts heads, Village heads, and key informants before the study commenced.

\subsection{Rapid Assessment Method}

On the schedule day, informed oral consent of individuals who gathered at the agreed venue (Village head compound, school or church premises) were sought and obtained after the explanation of the procedures and the benefit of the study and were examined for chronic clinical signs and symptoms of filariasis [18] [10]. Clinical symptoms, Lymphoedema of limbs, breast and Scrotal Elephantiasis were recorded in personal data form containing the patient's name. Female examination was restricted to the legs, arms and breast because of cultural inhibitions in most communities. Individuals with Lymphoedema of the limbs were classified according to the international society of lymphology as recommended by [19] as follows:

Grade 1 Lymphoedema: Lymphoedema without skin changes/thickening and fold. Oedema was reversible on elevation.

Grade 2 Lymphoedema: Lymphoedema with changes in skin texture but without folds. Oedema is not spontaneously reversible on elevation.

Grade 3 Lymphoedema: Lymphoedema with deep folds, with dermatosclerosis of Papillomatous lesion with knobs. Oedema was Irreversible. 


\subsection{Method of ICT Filariasis Test Kits (CTK Biotech Ink. San Diego, USA)}

Finger prick method was used between 9:00 and 18:00 GMT at a designated venue agreed upon by members of the community [20]. Blood sample was carried out according to manufacturer's instruction. Briefly, the patient's left index finger was cleaned with methylated spirit and then punctured using a sterile lancet. The pipette dropper enclosed in the ICT kit was used to suck 60 ul of blood and applied into the sample well in the device (cassette) making sure that air bubbles were removed, a drop of sample diluents was added immediately and the specimen migrated by capillary action across the cassette and read after 15 minutes. The test was read as positive if the test line " $T$ " and control line ' $C$ ' were seen in the viewing window. Any visible line on the test area indicated a positive test result even if it was lighter or darker than the ' $\mathrm{C}$ ' line. The test was regarded as negative if only the ' $\mathrm{C}$ ' line was seen and invalid if no line is seen on in the "C" line.

\subsection{Statistical Analysis}

Data obtained were entered in to computer, Microsoft Excel and Epi- info Version 7.0 was used for analysis.2-way ANOVA to compare and test for differences in infection among communities. Chi square analysis was used to determine if significant difference exist in the prevalence of antigenaemia by sex, age grouping and occupation. The result was considered significant at $\mathrm{p}<0.05$. Frequency distribution tables and percentage prevalence were estimated using standard formulae.

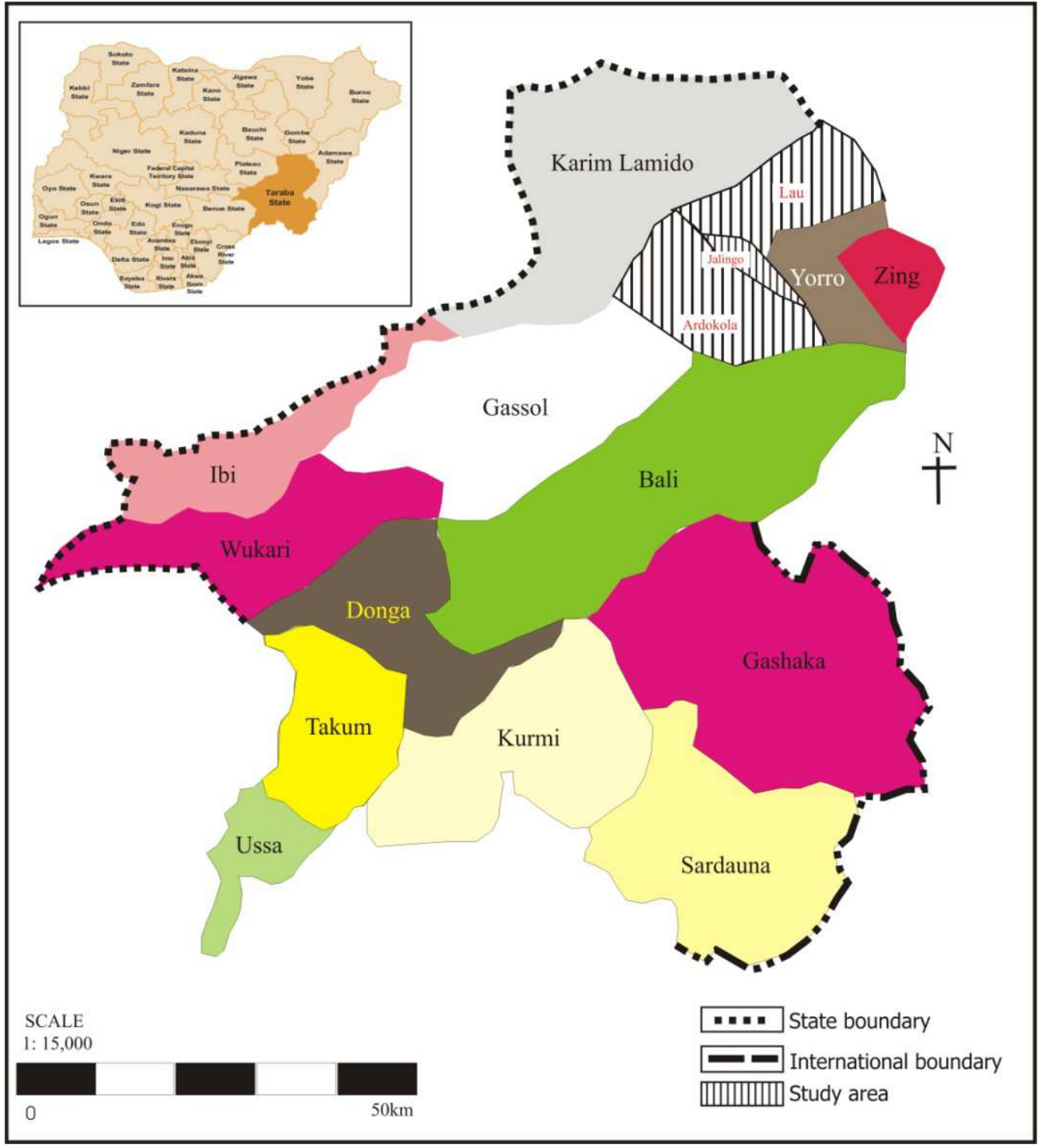

Figure 1. Map of Taraba State of Nigeria Showing the Study Location.

\section{Results}

A total of 336 individuals consisting of 181 males and 155 females from 11 communities of Northern Taraba state were examined using rapid Immuno Chromatographic Card Test to detect Circulating Filarial antigen (CFA) of $W$. bancrofti.

The overall prevalence in the study area was 101/336 
(30.05\%). The CFA prevalence among the 11 communities differed significantly (ANOVA, $\mathrm{p}<0.05$ ). The highest antigenaemia prevalence of $47.6 \%$ was observed in Nwagbala while, Sembe (18.2\%) showed the least prevalence (Table 1).

Gender related prevalence showed that males have higher prevalence $(32 \%)$ than the females $(27.7 \%)$. However, there was no significant difference between males and females prevalence in the study area $\left(\chi^{2}=0.491\right.$, df $\left.1, \mathrm{P}>0.05\right)$.

The prevalence increase with age in both sexes (Figure 2). There was statistically significant difference in the prevalence among the age groups $\left(\chi^{2}=11.424\right.$ df $\left.5, \mathrm{P}<0.05\right)$.

Grades of Lymphoedema were observed in the study area. The number of patients with Grade 1 is higher than Grade 2 and 3 respectively (Table 3 ).

Chronic clinical manifestation of the disease observed include Hydrocoel and Lymphoedema. A total 31/181 $(17.12 \%)$ of male who participated in the study had hydrocoel. The prevalence in relation to Lymphoedema showed that female have 50/336 (14.8\%) higher than male 27/336 (8.03\%) Table 3 .

Table 1. Distribution of W. Bancrofti Antigenaemia in 11 Communitiers of the Study Area.

\begin{tabular}{llll}
\hline Community & No. examined & No. positive & \% positive \\
\hline Dankodi & 21 & 9 & 42.8 \\
Garin Bako & 58 & 15 & 25.8 \\
Janibanbum & 53 & 11 & 20.7 \\
Jauro Ishaya & 28 & 10 & 35.7 \\
Jauro Votto & 22 & 7 & 31.8 \\
Lube & 47 & 13 & 27.6 \\
Murbai & 25 & 9 & 36.0 \\
Nwagbala & 21 & 10 & 47.6 \\
Sembe & 11 & 2 & 18.2 \\
Sobai & 20 & 4 & 20.0 \\
Vango & 30 & 11 & 36.6 \\
Total & 336 & 101 & 30.05 \\
\hline
\end{tabular}

Table 2. Sex-related W. Bancrofti Antigenaemia According to Communities in the Study Area.

\begin{tabular}{|c|c|c|c|c|c|c|}
\hline \multirow{2}{*}{ Community } & \multicolumn{2}{|l|}{ Male } & \multicolumn{2}{|l|}{ Female } & \multicolumn{2}{|l|}{ Total } \\
\hline & No. examined & No. +ve (\%) & No. examined & No. +ve (\%) & No. examined & No. +ve (\%) \\
\hline Dankodi & 14 & $7(50.0)$ & 7 & $2(28.6)$ & 21 & $9(42.8)$ \\
\hline Garin Bako & 26 & $10(38.5)$ & 32 & $5(15.6)$ & 58 & $15(22.8)$ \\
\hline Janibanbum & 26 & $4(15.3)$ & 27 & 7 (25.9) & 53 & $11(20.7)$ \\
\hline Jauro Ishaya & 14 & $3(21.4)$ & 14 & $7(50.0)$ & 28 & $10(35.7)$ \\
\hline Jauro Votto & 10 & $1(10.0)$ & 12 & $6(50.0)$ & 22 & $7(31.8)$ \\
\hline Lube & 20 & $8(40.0)$ & 27 & $5(18.5)$ & 47 & $13(27.6)$ \\
\hline Nwagbala & 11 & $4(36.4)$ & 10 & $6(60.0)$ & 21 & $10(47.6)$ \\
\hline Sembe & 9 & $2(22.2)$ & 2 & $0(0.0)$ & 11 & $2(18.2)$ \\
\hline Sobai & 13 & $3(23.1)$ & 7 & $1(14.2)$ & 20 & $4(20.0)$ \\
\hline Vango & 23 & $10(43.5)$ & 7 & $1(14.3)$ & 30 & $11(36.6)$ \\
\hline Total & 181 & $58(32.0)$ & 155 & $43(27.7)$ & 336 & $101(30.05)$ \\
\hline
\end{tabular}

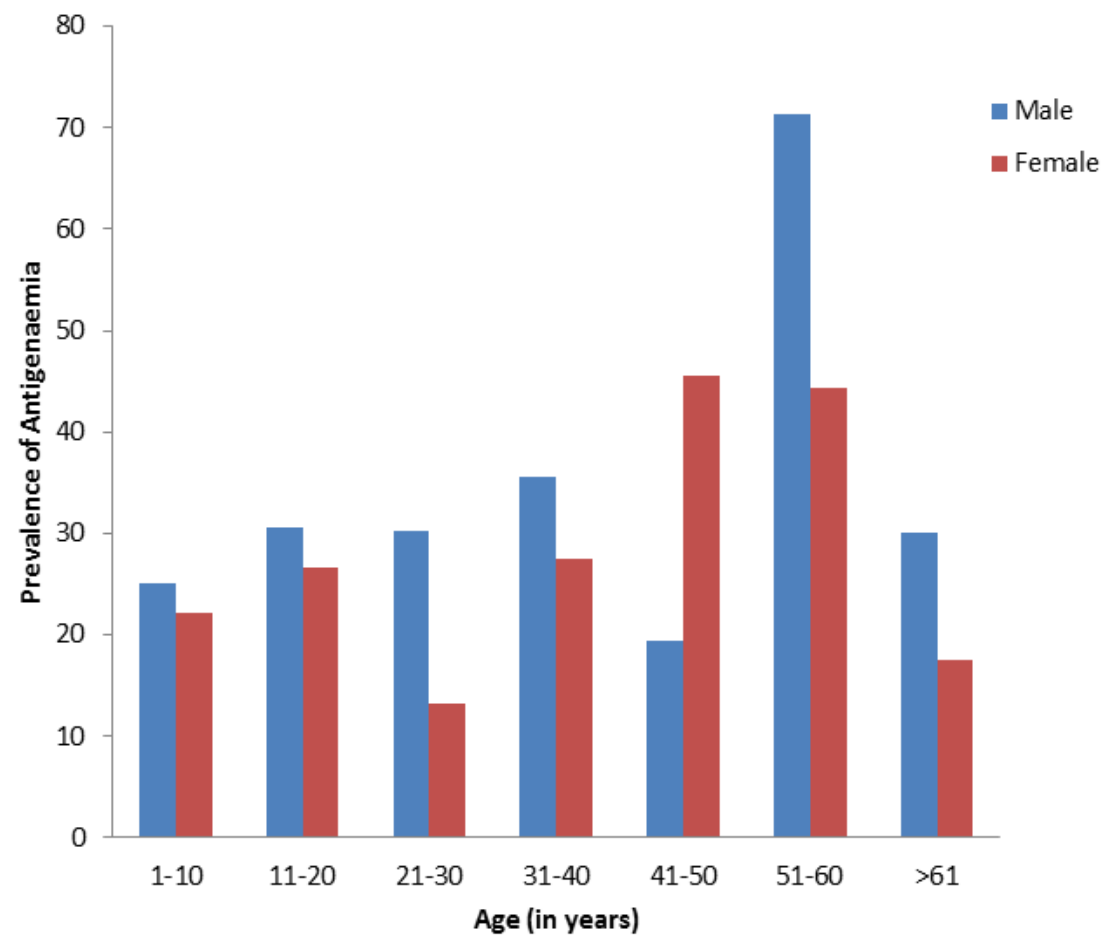

Figure 2. Prevalence of Antigenaemia According to Age and Sex in the Study Area, 2013. 


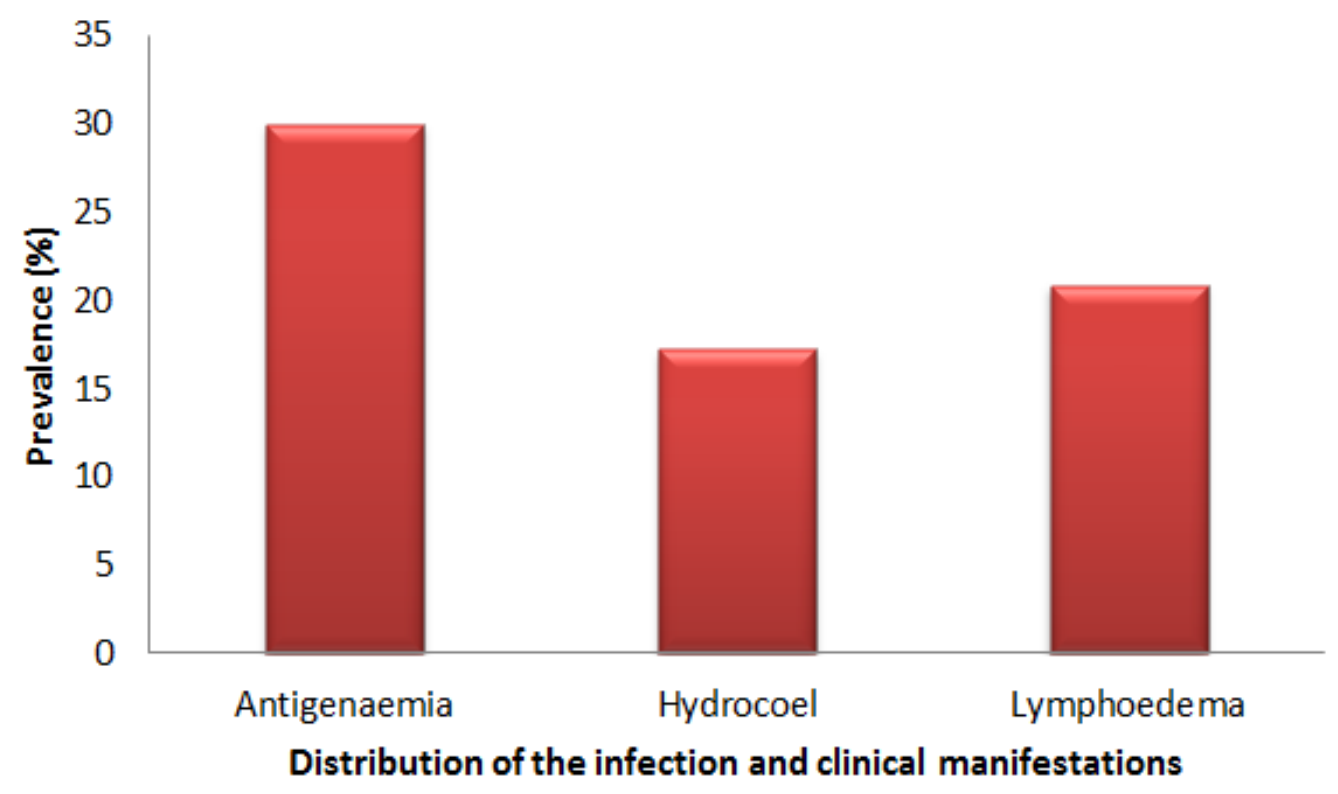

Figure 3. Prevalence of the Infection and Clinical Manifestations in the Study Area.

Table 3. Distribution of Grades of Lymphoedema in the Study Area According to Sex.

\begin{tabular}{|c|c|c|c|c|c|c|}
\hline \multirow{2}{*}{ Community } & \multirow{2}{*}{ No examined } & \multirow[b]{2}{*}{ No. with Lymphoedema } & \multirow{2}{*}{$\begin{array}{l}\text { Sex } \\
\text { No. }(\%)\end{array}$} & \multicolumn{3}{|c|}{ Grades of Lymphoedem: } \\
\hline & & & & 1 & 2 & 3 \\
\hline \multirow{2}{*}{ Dankodi } & \multirow{2}{*}{21} & \multirow{2}{*}{10} & M 3 (14.28) & 2 & 1 & 0 \\
\hline & & & F $7(33.3)$ & 4 & 2 & 1 \\
\hline \multirow{2}{*}{ Garin Bako } & \multirow{2}{*}{58} & \multirow{2}{*}{15} & M $2(3.4)$ & 2 & 0 & 0 \\
\hline & & & F $13(22.4)$ & 12 & 0 & 1 \\
\hline \multirow{2}{*}{ Janibanbum } & \multirow{2}{*}{53} & \multirow{2}{*}{9} & M $5(9.4)$ & 3 & 2 & 1 \\
\hline & & & F $4(7.5)$ & 4 & 2 & 1 \\
\hline \multirow{2}{*}{ Jauro Ishaya } & \multirow{2}{*}{28} & \multirow{2}{*}{11} & M $2(7.1)$ & 2 & 0 & 0 \\
\hline & & & F $9(32.1)$ & 6 & 2 & 1 \\
\hline \multirow{2}{*}{ Jauro Votto } & \multirow{2}{*}{22} & \multirow{2}{*}{7} & M 3 (13.6) & 0 & 2 & 1 \\
\hline & & & F 4 (18.2) & 3 & 0 & 1 \\
\hline \multirow{2}{*}{ Lube } & \multirow{2}{*}{47} & \multirow{2}{*}{4} & M $2(4.2)$ & 1 & 1 & 0 \\
\hline & & & F $2(4.2)$ & 1 & 1 & 0 \\
\hline \multirow{2}{*}{ Murbai } & \multirow{2}{*}{25} & \multirow{2}{*}{6} & M $1(4.0)$ & 1 & 0 & 0 \\
\hline & & & F $5(2.0)$ & 2 & 1 & 2 \\
\hline \multirow{2}{*}{ Nwagbala } & \multirow{2}{*}{21} & \multirow{2}{*}{9} & M $5(23.8)$ & 1 & 2 & 2 \\
\hline & & & F $4(19.0)$ & 2 & 2 & 0 \\
\hline \multirow{2}{*}{ Sembe } & \multirow{2}{*}{11} & \multirow{2}{*}{3} & M $1(9.0)$ & 1 & 0 & 0 \\
\hline & & & F $2(18.0)$ & 1 & 1 & 0 \\
\hline Sohai & 20 & 3 & M $3(15.0)$ & 2 & 1 & 0 \\
\hline Sobal & 20 & 3 & F $0(0.0)$ & 0 & 0 & 0 \\
\hline Vanoo & 30 & 0 & M $0(0.0)$ & 0 & 0 & 0 \\
\hline vango & & 0 & F $0(0.0)$ & 0 & 0 & 0 \\
\hline & & & M $27(8.03)$ & 15 & 9 & 4 \\
\hline Total & 336 & $77(20.8)$ & F $50(14.8)$ & 35 & 11 & 7 \\
\hline & & & $M+F=77$ & 50 & 20 & 11 \\
\hline
\end{tabular}

\section{Discussion}

Nigeria is believed to be the third most endemic country in the world after India and Indonesia [21]. This study provides the prevalence and the burden of Lymphatic filariasis in Northern Taraba focus. The overall prevalence of $30.05 \%$ among individuals in the eleven (11) communities despite the ongoing of MDA in some of the communities has further confirmed that Bancroftian Filariasis is widely distributed in Taraba state.
The prevalence observed in the study area here agreed with the work carried out in Brazil [22] and Kuwait. [23]. However, the prevalence of CFA in the present study was much higher than that of $6.45 \%$ observed in Benue state of Nigeria [24] and 21.13\% recorded in Afikpo North Ebonyi State Eastern Nigeria [25]. The high endemicity in these communities may be as a result of the availability of mosquito breeding sites and deteriorating sanitary conditions [26].

In the current study, the age related prevalence of CFA, there was an increase of prevalence by age. This is consistent 
with the observation in North central Nigeria [27]. However, contrast the findings was observed in Benue state, Nigeria [19] who recorded higher antigenaemia prevalence among the $40-49$ years. The ICT procedure was easy to use in the field and also very specific in detecting CFA compared to thick blood film preparation which is not convenient because of night blood collection [28].

Clinical examination and data collection procedures for the search of hydrocoel and Lymphoedema were convenient, simple and cost effective. The prevalence of hydrocoel encountered in this study is similar to those reported in other parts of Nigeria [9] [22]. Our findings support the recommendations for the use of hydrocoel and Lymphoedema as rapid community indicator for lymphatic filariasis endemicity [5] [11]. In the current study women formed a significant proportion of those affected with the disease probably because majority of them are farmers. Studies from other endemic areas have also reported that vast majority of Lymphoedema cases are women [24]. The study also revealed that $98 \%$ of Lymphoedema patients suffered from episodes of ADL attack. This is consistent with similar observation in other parts of the world [29]. The long period of exposure required before infection developing to potency could be responsible for the gradual increase of morbidity with age that is observed. Most affected people were the middle aged and elderly. The frequent attacks among farmers could be due to farming activities which often increased chances of sustaining the frequency of ADL attacks as observed by [30].

\section{Conclusion}

This study provided a rapid analysis of the status of the infection and its associated clinical manifestations in the study area. The high prevalence of LF in the study which is far above WHO threshold of $\geq 1 \%$ despite the ongoing Mass Drug Administration of Ivermectin and Albendazole in the state demand an urgent attention. We therefore recommend a more comprehensive and integrated method in the control of the infection in order to achieve the goal of eliminating the disease by the year 2020 .

\section{Acknowledgements}

We appreciate and thank the Chairmen and Directors Primary Health Care of Muri Emirate council, Commissioner and Permanent Secretary Ministry of Health, Taraba State collaborating to carry out this research. We appreciate the efforts of community Health workers that participated in data collection; we thank District heads that helped in mobilizing their subjects to participate in the study.

\section{Availability of Data and Materials}

Data sharing not applicable to this article as no datasets were generated or analysed during the current study.

\section{Funding}

The research was funded by Taraba State University Jalingo, Nigeria, through the Tertiary Institution Fund (TETFUND) grant Nigeria.

\section{Authors' Contributions}

ESO, EDS, KSL AGI. SAB and MAA contributed to study design and the first and subsequent manuscript drafts. ESO, EDS and ADE implemented the study and data analysis. ESO, KSL, AGI and SAB wrote the manuscript. All of the authors read and approved the final version of the manuscript.

\section{Competing}

There is no competing interest.

\section{Consent for Publication}

Not applicable in this section.

\section{Consent from Participants for Publication}

Not applicable to this study.

\section{Ethics Approval and Consent to Participate}

Ethics approvals were obtained from an institutional health research committee and ethical approval of Taraba state Ministry of Health. Also additional permission were sought and obtained from Local government chairmen, Primary Health Care (PHC) department.

\section{References}

[1] World Health Organization. 2013. Lymphatic filariasis: a handbook of practical entomology for national lymphatic filariasis elimination programmes, WHO Press, Geneva 27, Switzerland.

[2] Hotez P. J., Asojo O. A., and Adesina AM. 2012 Nigeria: "Ground Zero" for the High Prevalence Neglected Tropical Diseases. PLoS Negl Trop Dis 6: 1600:10.1371.

[3] McCarthy JS, Lustigman S, Yang G-J, Barakat RM, García HH, Sripa B, Willingham AL, Prichard RK, Basáñez M. 2012. A research agenda for helminth diseases of humans: diagnostics for control and elimination programmes. PLoS Negl Trop Dis., 6: e1601.

[4] McClay R (2006). Peters and Pasvol: Atlas of Tropical Medicine and Parasitology, $6^{\text {th }}$ edition, Elsevier Ltd.

[5] Addiss, D. G. and Brandy, M. A. 2007. Morbidity management in the Global Programme to Eliminate Lymphatic filariasis: A review of the scientific literature. Filarial Journal, 6:2 (doi: 10.1186/1475-2883-6-2). 
[6] World Health Organization (2017). Lymphatic filariasis: Epidemiology. Published by Division of Tropical Diseases. WHO, Geneva.

[7] World Health Organization (2011). Global programme to eliminate lymphatic filariasis: progress report. Wkly Epidemiol Rec 87: 346-356.

[8] Udoidung N I, Braide E I, Opara K O, Atting I A, Aide H A. (2008). Current status of bancroftian filariasis in rural communities of the lower Cross River basin, Nigeria: Parasitological and clinical aspects. J Pub Hlth.; 9:23-27.

[9] Okon OE, Iboh CI, Opara K. N. 2010. Bancroftian filariasis among the Mbembe people of Cross River State, Nigeria. Journal of Vector Born Dis47: 91-96.

[10] Jorge Cano, Maria P Rebollo, Nick Golding, Rachel L Pullan, Thomas Crellen, Anna Soler, Louise A Kelly- Hope, Steve W Lindsay, Simon I Hay, Moses J Bockarie and Simon J Brooker (2014). The global distribution and transmission limits of lymphatic filariasis: past and present, Parasites \& Vectors 20147:466.

[11] Nwoke, B. E. B., Dozie, I. N. S., Jiya, J., Saka, Y., Okoronkwo, C., Ogidi, J. A., Istifanus, W. A., Mafiana, C. F., Oyene, U., Amalio, O., Ogbu-Pierce, P., Audu, G., Remme, H., and Nuttal, I. (2006). The prevalence of hydrocoel in Nigeria and its implication on mapping of lymphatic filariasis. Nigerian Journal of Parasitology. Vol 27: 29-35.

[12] Terranella, A., Eigege, A., Gontor, I., Dogwa, P., Damishi, S., Miri, E., Blackburn, B., McFarland, D., Zingeser, J., Jinadu, M. Y and Richards, F. O (2006). Urban lymphatic filariasis in central Nigeria. Annals of Tropical Medicine and Parasitology. 100(1): 1-10.

[13] World Health Organization (1997). Lymphatic filariasis: Reasons for hope. Published by Division of Tropical Diseases. WHO, Geneva.

[14] World Health Organization (2016). Global programme to eliminate lymphatic filariasis: progress report. Weekly epidemiological record 91, 441-460.

[15] Gyapong, M., Gyapong, J., Weiss, M and Tanner, M. (2000). The burden of hydrocoel on men in Northern Ghana. ACTA Tropica. 77(3): 287-294.

[16] Dziedzom Komi de Souza, Jewelna Osei-Poku, Julia Blum, Helena Baidoo, Charles Addoquaye Brown, Bernard Walter Lawson, Michael David Wilson, Moses John Bockarie and Daniel Adjei Boakye (2014). The epidemiology of lymphatic filariasis in Ghana, explained by the possible existence of two strains of Wuchereria bancrofti. Pan Afr Med J. 17: 133. doi: 10.11604

[17] Nigerian National Population Census, (2006). Published by Nigeria Population Commission Abuja, Nigeria.

[18] Edungbola, L. D., Nwoke, B. E. B., Onwuliri, C. V., Akpa, A. U. C. and Tayo-Mafe, M. (1993). Selection of Rapid Assessment methods for community diagnosis of onchocerciasis in Nigeria. A recapitulation. Nigerian Journal of Parasitology. 14: 3-10.
[19] World Health Organization (1992). Lymphatic filariasis: the disease and its control. Fifth report of the WHO expert committee on filariasis. Geneva: World Health Organization Technical Report Series. No 82. WHO, Geneva. Pp 25.

[20] Chesbrough, M (2005). District Laboratory Practice in Tropical Countries (second edition updated). Cambridge University Press New York. Pp 280- 290.

[21] Braga, C., Dourado, M. L., Ximenes, R. A., Alves, L., Brayner, F., Rochas, A and Alexander, N (2003). Field evaluation of the whole blood immunochromatographic test for rapid bancroftian filariasis diagnosis in the North East of Brazil. Rev. Inst. Med. Trop. Sao Paulo. 45: 125-129.

[22] Iqbar, J. I and Sher, A (2006). Determination of the prevalence of lymphatic filariasis among migrant workers in Kuwait by detecting circulating filarial antigen. Journal of Medical Microbiology. 55:401-405.

[23] Targema, C. N., Onwuliri, C. O. E., Mafuyai, H. B., Mwansat, G. S., Aida, A., Eigege, A., Ityonzughul, C., Kal, A., Orkurga, B and Junaidu, M. Y (2008). Mapping of lymphatic filariasis in Benue state, Nigeria. Nigerian Journal of Parasitology. 29(1): 55-61.

[24] Eigege A, Richards F O, Blaney D D, Miri E S, Gontor I, Ogah G, Umaru J, Janadu M Y, Matthias W, Amadiegwu S, Hopkins D R. 2003. Rapid assessment for lymphatic Filariasis in central Nigeria: a Comparison of the Immunochromatographic card test and hydrocoele rates in an area of high endemicity. Am J Trop Med Hyg.; 68(6):643646.

[25] Omudu, E. A and Okafor, F. C (2007). Rapid epidemiological and social-cultural appraisal of lymphatic filariasis amongst the Igede ethnic group in Benue State, Nigeria. Nigerian Journal of Parasitology. 28(2):118-124.

[26] Anosike, J. C., Onwuliri, C. O. E., Nwoke, B. E. B., Ajayi, E. G., Oku, E. E., Asor, J. E (2005). Lymphatic Filariasis among the Ezza people of Ebonyi State, Eastern Nigeria Annals of Agriculture and Environmental Medicine. 12: 181-186.

[27] Elkanah, S. O., Onyeka, J. O. A., Anyanwu, G. I., Madara, A. A and Debby-Sambo, D. E (2011). The prevalence of Bancroftian filariasis in Five Communities of Lau L. G. A Taraba Stat The Nigeria Journal of Parasitology 23 (2); 157164.

[28] Lammie, J. P., Addis, D. G., Leonard, G., Hightower. A. W and Eber hard, M. L (1993). Heterogeneity in filarial-specific Immune responsiveness among patients with lymphatic obstruction. Journal of Infectious Diseases. 167: 1178-1183.

[29] Kar, S. K., Maria, J and Kar, P. K (1993). Humeral Immune response during filarial fever in bancroftian filariasis. Transaction of the Royal Society of Tropical Medicine and Hygiene. 87: 230-237.

[30] Badaki, J. A. and Akogun, O. B. (2001): Severe morbidity due to lymphatic filariasis in Taraba State, Nigeria. The Nigerian Journal of Parasitology. 21: 105-112. 